\title{
TECHNOLOGY PARK IN CONNECTION WITH NATIONAL FILING OF RADIOACTIVE WASTE
}

\author{
F. CUMO, B. DE LIETO VOLLARO, E. PENNACCHIA, M. SFORZINI \& V. SFORZINI \\ Sapienza University of Rome, Italy.
}

\begin{abstract}
The starting project idea arises from the need to provide a national disposal for radioactive waste as required by the European Union, in order to adjust Italy to the rest of the other European countries. The site will replace the temporary disposals realized near to the four former nuclear plants in the Italian territory, to permit plants decommissioning and the subsequent environmental rehabilitation of those areas. The disposal will be realized according to the most modern standards of environmental safety and ensuring maximum sustainability of the site thus using all the 'Best Available Technique' for the construction of Near Zero Energy Buildings and energy production systems from renewable sources. The Project is based on data coming from SOGIN (the Italian society for the decommissioning of nuclear plants) for the national radioactive waste disposal able to contain 90,000 cubic meters of radioactive waste and divided into two parts, allowing separate storage of the waste of first and second level, respectively, in quantities of $15.000 \mathrm{mc}$ and $75.000 \mathrm{mc}$. The Technology Park close to the disposal, will be done with maximum transparency criteria, so to make the site not only accessible to citizens, but even a tourist attraction and a meeting area for the scholars, university students and researchers. In this technological park there are strong requirements for high security systems and an adequate transport and mobility plan designed even for critical situations. In fact in the designed Park there are even special protection systems from physical agents with the possibility, in case of danger, of an access to the closed collection points that are able to insulate workers and visitors from fire or radiation danger.
\end{abstract}

Keywords: decommissioning, environmental, radioactive waste, sustainability, technology.

\section{INTRODUCTION}

A national disposal for radioactive waste should be designed in Italy to replace the temporarily disposals starting from the data collected by SOGIN (the Italian society for the decommissioning of nuclear plants) with this purpose [1-3]. Moreover, site selection methods for this kind of disposals should include an analysis of environmental, economic and social criteria [4], as well as a multi-criteria decision making (MCDM) approach [5].

GIS (geographical information systems) have been often used for these studies analysing in digital query maps, environmental characteristics and human uses of considered areas [6].

The National deposit has been conceived as a waste storage system and placed into a Technology Park with research facilities and training, particularly in the field of management of radioactive waste and spent fuel. The park has the guarantees and special compensations for the territory, ready to accommodate the new structure and will be activated with an extremely transparent process and participatory location.

The concept underlying the planned park is linked to a creative fusion among science, nature and man. The developed project tries to get the maximum integration of main areas 
covered by the introduction of the minimum number of elements that enable us to maintain the green as the principal 'actor'. The close relationship between architecture and nature is expressed through the reproduction of a leaf, with its forms and functions in a wide space dedicated to environment. The buildings, integrating technical and nanotechnology systems, will in fact be able to capture solar radiation, to store rainwater and filter pollutants in the air; everything is designed in compliance with the principles of environmental sustainability.

The issue concerning the object of the technology park is developed through the 'most common iconographic image of nuclear power technology; the atom. In the project we use the electron orbits as an element of aggregation and meeting between the office staff and visitors. The electrons have been designed as a food court and the orbits correspond to internal pathways for sustainable mobility for pedestrian, bicycle and electric elevated rail with a train able to host up to 100 people.

The project of the Technology Park, has been designed with a square shape, measuring $632.45 \mathrm{~m}$ for the side and 400,000 sqm (40 hectares) of surface. The lot is divided into two equal zones of 20 ha each, respectively assigned to the settlement and expansive areas.

The project provides a first phase of intervention which considers the IF (manufacturability index) of 0.5 for the settlement area, with a relative volume of 100,000 cubic meters, and a later with the IF of 0.35 for the expansive area, with a volume of 70,000 cubic meters.

The destinations of the different areas have been defined on the basis of percentage weights relative to the total according to the schemes in Tables 1 and 2.

The allocation of parking spaces for the entire lot has been established considering 1 place for each 2 persons, and 200 places added for the visitors. The parking lots are distributed in the peripheral areas of the two lots, near of the functional areas so not to generate excessive traffic in the central zones, which are mainly for walking and cycling.

Table 1: Division into areas and intended use of the technology park.

\begin{tabular}{lcc}
\hline \multicolumn{3}{c}{ 1. Settlement Area, IF 0,5 mc/mq $=100.000 \mathrm{mc}$} \\
\hline Use's zone & $\%$ & $\mathrm{MC}$ \\
\hline Administration & 12 & 12.000 \\
Research & 30 & 30.000 \\
Production and development & 25 & 25.000 \\
Reception and refrechments & 15 & 15.000 \\
Dissemination and promotion & 10 & 10.000 \\
Support service to the deposit & 8 & 8.000 \\
\hline \multicolumn{1}{c}{ 2. Expansive Area, IF 0,35 mc/mq $=70.040 \mathrm{mc}$} \\
\hline Use's zone & $\%$ & $\mathrm{MC}$ \\
\hline Research & 26 & 18.200 \\
Production and development & 26 & 18.200 \\
Reception and refrechments & 21 & 15.000 \\
Dissemination and promotion & 27 & 10.000 \\
\hline
\end{tabular}


Table 2: Distribution and zoning of the technology park.

\begin{tabular}{|c|c|c|}
\hline Building destination & $n^{\circ}$ & Building area distribution \\
\hline Building for administrative use & 2 & 2 In area 1 \\
\hline Building for research and a development & 10 & 6 In area 1 and 4 in area 2 \\
\hline Restaurants and bar & 8 & 4 In area 1 and 4 area 2 \\
\hline Conference hall & 1 & Area 1 \\
\hline Hotels and hospitality & 4 & 2 In area 1 and 2 in area 2 \\
\hline Museum & 1 & Area 1 \\
\hline Buildings for promotion and dissemination & 4 & 1 In area 1 and 2 in area 2 \\
\hline Building for access security & 5 & 3 In area 1 and 2 in area 2 \\
\hline Sport facilities & 1 & 1 In area 2 \\
\hline
\end{tabular}

THE TECHNOLOGY PARK

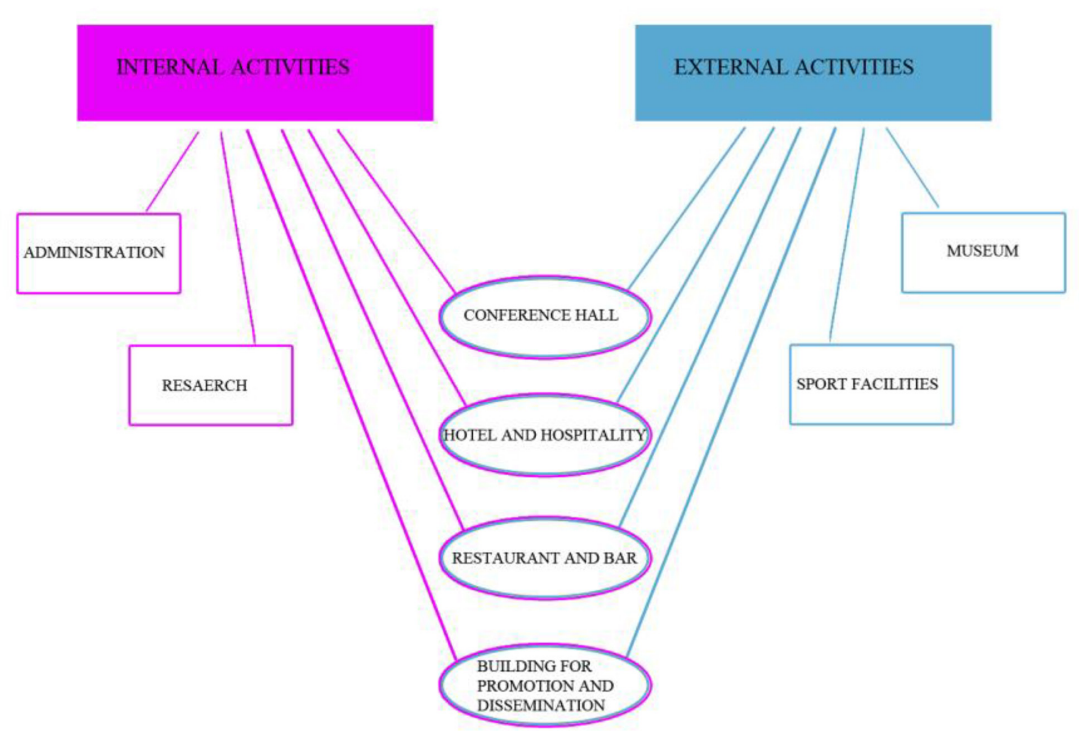

Figure 1: schematic drawing of the technology park.

\section{AIM OF THE PROJECT}

The Technology Park is a 'work related to the National Storage of radioactive waste. The radioactive waste from nuclear medicine will be accommodated in the surface infrastructure together with industrial, research activities and the Italian nuclear plants, which is going to be dismantled nowadays. Both of them integrate with the territory and the environment, emphasizing the context in which they occur. The Technology Park is a research and training center dedicated to the international level, in particular, to studies in the field of decommissioning of nuclear installations, management of radioactive waste and environmental protection. The realization of the park and the areas around it, have the purpose of allowing the host 


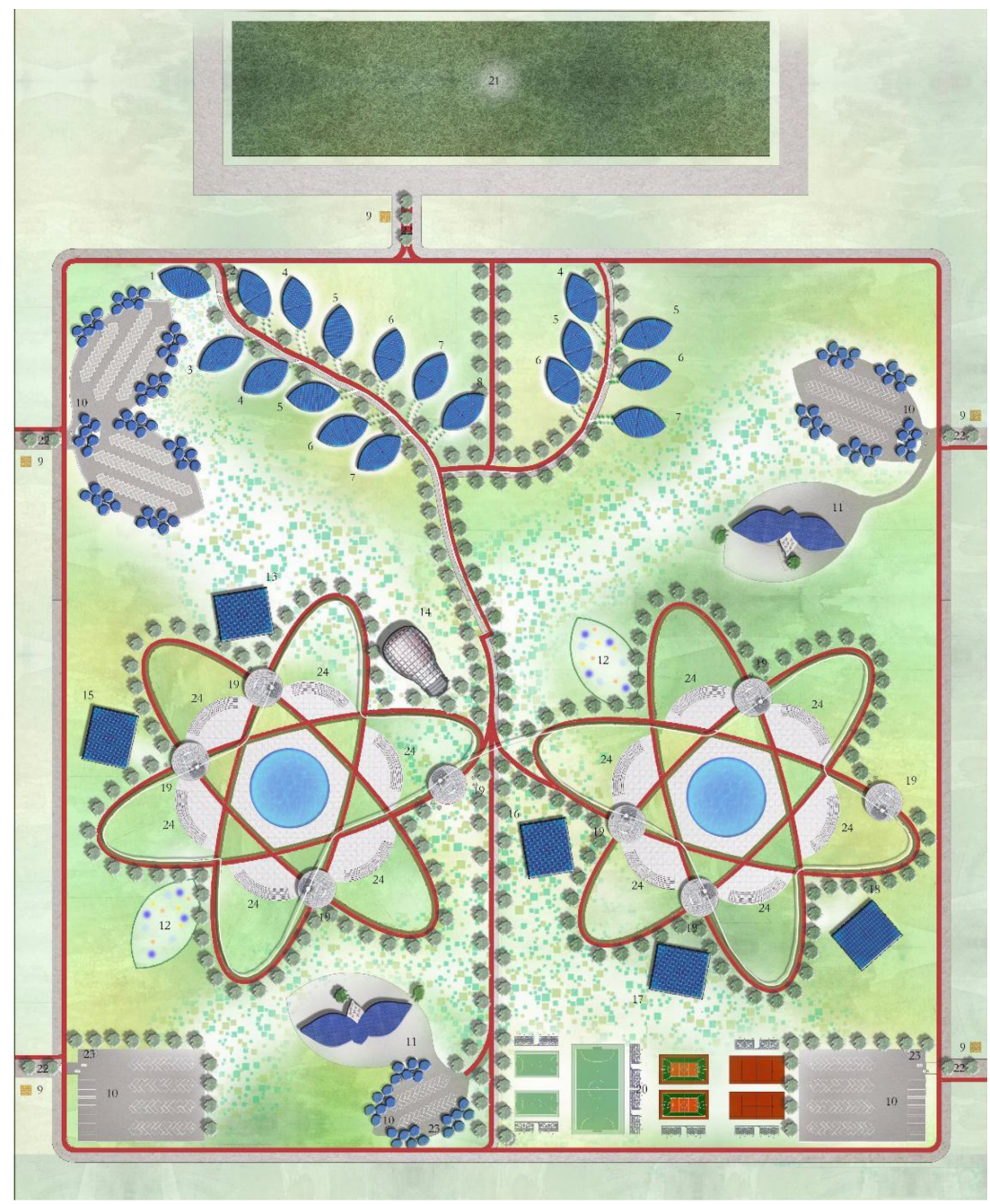

Figure 2: Plan park.

community to have an attractiveness area and a high technological significance. The structure will be able to inspire positive suggestions aimed at the integration of the center with the context around it and at the same time promote the socio-economic development of the host country. In this way, the communities that host the deposit will have the opportunity to have a 'structural' attractive and a high technology model, which represents an added value and a hallmark for the territory.

\section{URBAN AND ARCHITECTURAL QUALITY}

The main functional areas are connected together by a perimeter road network, an internal path and by several accesses to the park. The built-up area is homogeneously diffused throughout the lot allowing a connection of the green zones without solution of continuity, while connoting specifically each zone with its intended use, namely: 


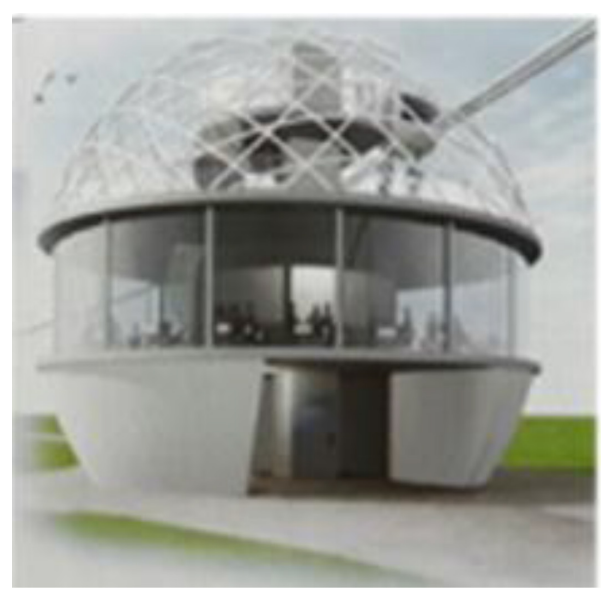

Figure 3: Restaurant.

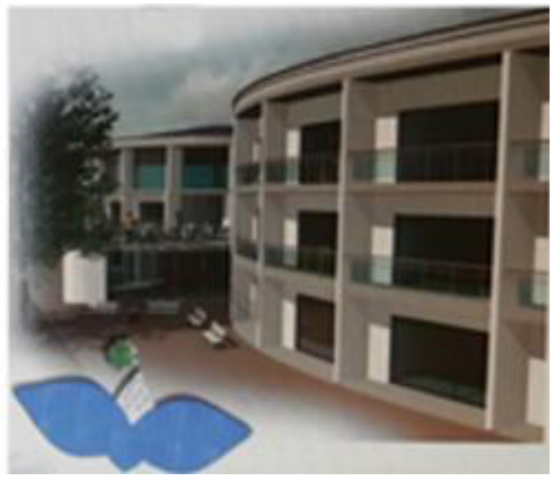

Figure 4: Guesthouse.

- Administration and support services to the deposit;

- Reception and refreshments;

- Dissemination and Promotion.

- Production and development;

- Basic research.

The entire park is designed to be up and running with the construction of buildings in the settlement. In the expansion lot, having a low index of manufacturability, it is possible to exploit the flexibility of the buildings 'leaf' replicating and adding additional modules, since each building is functionally and energetically autonomous. The office buildings and reserved parking areas have been projected near the entrance to the store to ensure an optimization of the movements. The central area is dedicated to catering and recreational and leisure areas, such as small outdoor amphitheaters, sensory pathways and play area for the kids as well as those aimed at science museums, academic centers and auditoriums. The parking spaces reserved to visitors are located in the opposite area of the deposit, as well as the guesthouse and several sports facilities, which can also be enjoyed outside the context of the technology park. The road system is primarily designed to encourage pedestrian and cycle movement throughout the lot. The surface layer of bike paths and green routes will be made with consolidation systems using nanotechnology. The pedestrian and cycle paths will be accessible everywhere to reach any area. The viability of electric rail system provided in the central area, which has also been designed for recreational and refreshment activities, is based on an automatic drive system with four wagons, able to serve up to a maximum of 100 people. The system can be used for both playful and functional purposes and is operated by an electric engine to a rack system service. With regard to largest buildings, [7] in accordance with environmental sustainability criteria, to reduce constructions times, it has been conceived a prefabricated system for insulated concrete walls and laminated wood for the roofs; this solution also optimizes the maintenance procedures guaranteeing significant energy performance [8]. For smaller buildings it has been chosen a prefabricated system of laminated wood. Each structure is equipped with photovoltaic panels and rainwater recovery systems. For the entire surface of the buildings it will be used a photocatalytic paint that will make a significant contribution to air quality through self-cleaning action, anti-pollution and anti-bacterial. 


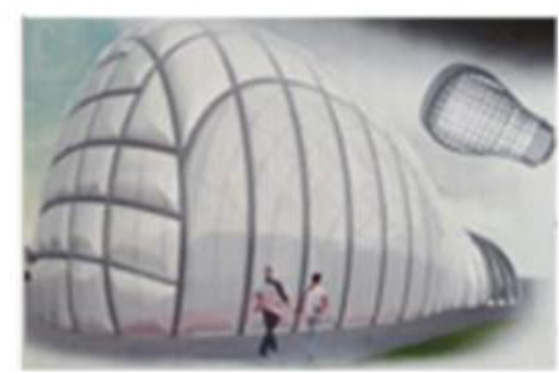

Figure 5: Conference room.

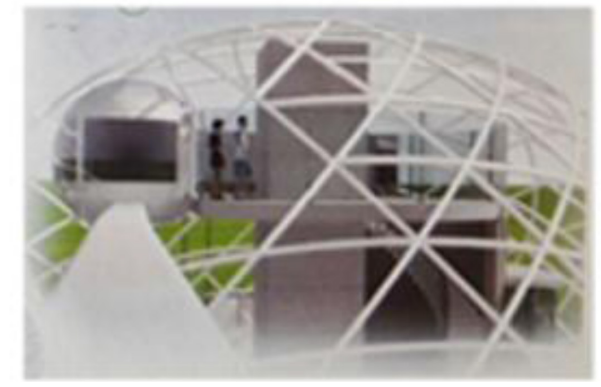

Figure 6: train stop on the top of the restaurant.

\section{ENVIRONMENTAL SUSTAINABILITY}

The harmony between the existing natural environment and the built environment will be obtained creating works that enable rapid development of green allowing nature to reclaim the area; in respect of this philosophy it will not be created any micro ecosystems with nonnative plantings.

Pursuing the objective of replicating the outside habitat, a recovery system for waters coming from cemented areas has been designed in order to recover as much water as possible, in special channels. Therefore, the pond in the center of the atom has also been designed with the water reserve function for sprinklers and irrigation of green areas, using bioengineering techniques that cement interventions that create an impermeable barrier to life [9].

\subsection{Reduction of land consumption}

The reduction of land consumption is a fundamental requirement of the project. Prefabricated buildings permit reduction of foundation excavation, limiting them to concrete slab and poles; so that the entire area of intervention will return in the pre-works state without any difficulty.

\subsection{Site energy balance}

The design requirements allow to get the buildings classification as NZEB - Nearly Zero Energy Buildings (max $10 \mathrm{kWh} / \mathrm{sqm}$ year of energy consumption). The characteristics of Italian territorial morphology do not permit a sufficient reliance on alternative energy sources such as geothermal or wind or biomasses; indeed the use of these technologies should be preliminarily analysed considering their feasibility and impacts on the surrounding areas $[10,11]$. In particular, in this project therefore haves been used only solar energy systems by limiting the height of the buildings and increasing the surface area in plan view, installing photovoltaic panels and solar collectors. The system is integrated by specific elements shaped like 'photovoltaic trees' installed near the parking. The proposed energetic grid is able to produce around $2 / 2.5 \mathrm{MW}$ of power; this variability is due to the lack of radiation data because the location site of the disposal has not been decided by Italian nuclear authorities. The energy production is expected between 2,600,000 and 3,200,000 $\mathrm{kWh}$ per year, which is able to supply about $40 \%$ of the energetic loads of the entire technology park. This includes thermal, electrical and electronic buildings consumption, park lighting and electric mobility loads, including rail [12]. In addition, for an additional decarbonisation of the site energy 
balance, the integration with a combined heat and power plants (CHP) using hydrogen enriched natural gas blends [13-16] has been considered.

\subsection{Water conservation, rainwater collection and purification of waste water}

The pond, which is at the center of the park, play a multipurpose role from an environmental and safety point of view. The aim is to exploit the natural slope of the ground and the presence of different vegetation providing the natural habitat for animals and plants and enhancing man's relationship with nature. At the same time such a large pond, can be used as an emergency reserve for the fire extinguishing system.

\subsection{Innovation in the waste cycle management}

The project philosophy is aimed to reduce waste production following the European Union directive on the package 'waste directives' (waste, packaging, landfills, vehicles, batteries and accumulators). Specifically, the project involves the collection and disposal of waste through recycling, performed by electrical carriers that carry waste towards a collection center, which can also be used by external users to the park.

\section{CONCLUSIONS}

The creation of a nuclear waste disposal is a need not be postponed for Italy. Its acceptability by the population depends on management transparency and positive effects on the territory. Consequently, the choice to join the waste disposal with a technology park able to accommodate research laboratories, innovative start-ups and at the same guests which students of various grade schools and families, is the only one able to meet the two requirements mentioned above. The sustainable design criteria used in the project also allow us to limit the environmental impact of the structures both for land use and deployment of the existing energy infrastructure; through the project realization it will be possible to spread knowledge of the best available technique (BAT) even in areas different from traditional urban settings.

\section{REFERENCES}

[1] Guidi, G., Decommissioning degli impianti nucleari e gestione dei rifiuti radioattivi, Gangemi Editore spa, 2011.

[2] Noviello, L., Di Giuseppe, P. \& Ruggeri, G., Decommissioning degli impianti nucleari - Normativa tecnica, Arti grafiche Tilligraf srl, 2004

[3] Cumo, M., Tripputi, I. \& Spezia, U., Nuclear Plants Decommissioning, Sapienza Università di Roma, 2002.

[4] Guido, G., Gugliermetti, F., Astiaso Garcia, D. \& Violante, A.C., Influence of environmental, economic and social factors on a site selection index methodology for a technological centre for radioactive waste management. Chemical Engineering Transactions, 18, pp. 505-510, 2009.

[5] Di Matteo, U., Pezzimenti, P.M. \& Astiaso Garcia, D., Methodological proposal for optimal location of emergency operation centers through multi-criteria approach. Sustainability, 8(1), pp. 1-12, 2016. http://dx.doi.org/10.3390/su8010050

[6] Gugliermetti, F., Cinquepalmi, F. \& Astiaso Garcia, D., The use of environmental sensitivity indices (ESI) maps for the evaluation of oil spill risk in Mediterranean 
coastlines and coastal waters. WIT Transactions on Ecology and the Environment, 102, pp. 593-600, 2007.

http://dx.doi.org/10.2495/sdp070572

[7] Cumo, F., Di Matteo, U. \& Sforzini, V., Sistemi tecnologici per edifici a energia quasi zero, Esculapio Editrice, 2013

[8] Carbonara, E., Tiberi, M. \& Astiaso Garcia, D., Analysis of energy performance improvements in Italian residential buildings. Energy Procedia, 82, pp. 855-862, 2015. http://dx.doi.org/10.1016/j.egypro.2015.11.826

[9] De Santoli, L., Astiaso Garcia, D. \& Violante, A.C., Planning of flood defence management and rehabilitation of the natural habitat in the downstream part of the river Tiber. WIT Transactions on the Built Environment, 100, pp. 25-34, 2008. http://dx.doi.org/10.2495/GEO080031

[10] Astiaso Garcia, D., Canavero, G., Ardenghi, F. \& Zambon, M., Analysis of wind farm effects on the surrounding environment: assessing population trends of breeding passerines. Renewable Energy, 80, pp. 190-196, 2015. http://dx.doi.org/10.1016/j.renene.2015.02.004

[11] Astiaso Garcia, D., Sangiorgio, S. \& Rosa, F., Estimating the potential biomasses energy source of forest and agricultural residues in the Cinque Terre Italian National Park. Energy Procedia, 82, pp. 674-680, 2015. http://dx.doi.org/10.1016/j.egypro.2015.11.791

[12] Cumo, F., SoURCE Sustainable Urban Cells, U. Quantily spa, 2011.

[13] De Santoli, L., Lo Basso, G. \& Bruschi, D., Hybrid system with an integrated CHP plant fueled by H2NG blends: Theoretical energy-environmental analysis and foreseeable optimizations. Energy and Buildings, 7, pp. 88-94, 2014. http://dx.doi.org/10.1016/j.enbuild.2013.12.008

[14] De Santoli, L., Lo Basso, G. \& Bruschi, D., Energy characterization of CHP (combined heat and power) fuelled with hydrogen enriched natural gas blends. Energy, 60 , pp. 13-22, 2013.

[15] De Santoli, L., Lo Basso, G. \& Bruschi, D., Preliminary experimental analysis of a CHP hydromethane system. Journal of Power and Energy Engineering, 7, pp. 1681-1690, 2013. http://dx.doi.org/10.1016/j.energy.2013.07.012

[16] De Santoli, L., Lo Basso, G. \& Bruschi, D., A small scale H2NG production plant in Italy: techno-economic feasibility analysis and costs associated with carbon avoidance. International Journal of Hydrogen Energy, 39, pp. 6497-6517, 2014. http://dx.doi.org/10.1016/j.ijhydene.2014.02.003 